medRxiv preprint doi: https://doi.org/10.1101/2022.01.13.22269221; this version posted January 13, 2022. The copyright holder for this preprint (which was not certified by peer review) is the author/funder, who has granted medRxiv a license to display the preprint in All rights reserved. No reuse allowed without permission.

\title{
Genetic overlap between Parkinson disease and inflammatory bowel disease
}

\author{
Xiaoying Kang, ${ }^{1}$ Alexander Ploner, ${ }^{1}$ Yunzhang Wang, ${ }^{1}$ Jonas F. Ludvigsson, ${ }^{1,2}$ Dylan M. \\ Williams, ${ }^{1,3}$ Nancy L. Pedersen, ${ }^{1}$ Karin Wirdefeldt ${ }^{1,4}$ \\ ${ }^{1}$ Department of Medical Epidemiology and Biostatistics, Karolinska Institutet, Sweden \\ ${ }^{2}$ Department of Pediatrics, Örebro University Hospital, Sweden \\ ${ }^{3}$ MRC Unit for Lifelong Health and Ageing, University College London, UK \\ ${ }^{4}$ Department of Clinical Neuroscience, Karolinska Institutet, Sweden
}

Corresponding to: Xiaoying Kang; Department of Medical Epidemiology and Biostatistics, Karolinska Institutet, Nobels väg 12A, 17165 Solna, Sweden; e-mail: xiaoying.kang@ki.se

\begin{abstract}
Importance Parkinson disease (PD) and inflammatory bowel disease (IBD) have been associated, implying shared pathophysiology. Characterizing genetic pleiotropy between the two conditions aids the exploration of common etiology.
\end{abstract}

Objective To estimate the genetic correlation between PD and IBD and to identify specific loci influencing both conditions.

Design Genetic study with applications of high definition likelihood and conditional false discovery rate (FDR) framework.

Setting The study was based on summary statistics of genome-wide association studies (GWAS).

Participants The PD GWAS comprised 37,688 cases and 981,372 controls, and the IBD GWAS included 25,042 cases and 34,915 controls. Participants were of mixed ethnicity.

Exposures None.

Main Outcomes and Measures The main outcomes were a set of single nucleotide polymorphisms (SNPs) identified by conditional FDR analysis as jointly associated with PD and IBD.

Results Weak but statistically significant genetic correlations were detected for PD with both Crohn's disease (CD) and ulcerative colitis (UC), the two main subtypes of IBD. A total of 1333 SNPs in 28 genomic loci and 1915 SNPs in 22 loci were jointly associated with PD-CD and PD-UC, respectively, at conjunctional FDR under 0.01. The pleiotropic loci appeared distinctive for PD-CD and PD-UC, are mostly novel and comprise loci with either same or opposing genetic effects on the two phenotypes. Positional and eQTL mapping prioritized 316 PD-CD and 303 PD-UC genes, among which only $<10 \%$ are differentially expressed in both colon and substantia nigra. The KEGG pathways enriched by all prioritized genes were highly concordant between PD-CD and PD-UC, with the majority being related to immune and/or autoimmune dysfunction.

Conclusions and Relevance Overall, we found robust evidence for a genetic link between PD and each subtype of IBD. The identified genetic overlap is complex at the locus and gene levels, indicating the presence of both common etiology and antagonistic pleiotropy. At the functional level, our results highlighted a central role NOTE: This preprint reports new research that has not been certifieg by peor review and should not be used to guide clinical practice.
Of host 1mhmunity and/or autolmmunity in the PD-IBD relationship. 
medRxiv preprint doi: https://doi.org/10.1101/2022.01.13.22269221; this version posted January 13, 2022. The copyright holder for this preprint (which was not certified by peer review) is the author/funder, who has granted medRxiv a license to display the preprint in All rights reserved. No reuse allowed without permission.

Kang $\mid 2$

\section{Introduction}

Parkinson disease (PD) is a neurodegenerative movement disorder with no curative or disease-modifying therapies, suggesting an urgent need for better understanding of disease pathophysiology to foster drug discovery. The gut-brain axis has been hypothesized to play a role in PD pathogenesis, stimulating a growing body of work on the putative contribution of gastrointestinal dysfunction in PD initiation. ${ }^{1,2}$ Inflammatory bowel disease (IBD) is a chronic intestinal inflammatory condition manifested by long-lasting diarrhea, abdominal pain and bloody stool. ${ }^{3}$ Recently, a meta-analysis of nine observational studies comprising over 12 million patients demonstrated an interesting bidirectional relationship between PD and IBD, as well as a protective effect of anti-inflammatory medications on PD among IBD patients. ${ }^{4}$ The observed IBD-PD correlation was further strengthened by subsequent epidemiological findings, which collectively indicated a biological link between the two seemingly unrelated conditions. ${ }^{5,6}$ The onset of PD-like neuropathology and motor function impairment in an animal model for IBD also supported the involvement of intestinal inflammation in PD initiation and progression. ${ }^{7}$

How the inflamed gut and its underlying mechanisms are intrinsically connected to PD remains elusive. A sophisticated interplay between mucosal immunity and intestinal microbiota, two key drivers in IBD, has been shown to be relevant. ${ }^{8-10}$ Mechanistically, the inflammation-associated disruption of the intestinal epithelial barrier facilitates the translocation of microbial products from the intestinal lumen into the peripheral circulation, inducing gut dysbiosis and systemic inflammation. ${ }^{11}$ These events next trigger upregulation of $\alpha$-synuclein (the PD pathogenic protein) expression and its abnormal aggregation in enteric neurons, as well as neuroinflammation, which promotes neurodegeneration in the brain. ${ }^{12,13}$

Discovery of genetic overlap between PD and IBD has shed new light into the molecular underpinning shared by the two diseases. For instance, polymorphisms of the leucine-rich repeat kinase 2 (LRRK2) gene have been robustly associated with susceptibility of both PD and Crohn's disease (CD), a subtype of IBD, corroborating the crucial role of the immune system in the two conditions. ${ }^{14,15}$ Owing to the methodological advancement in crossphenotype pleiotropic analyses, additional common genetic determinants of PD and IBD have been identified. ${ }^{16}$ Hence, to further test the PD-IBD connection genetically and to uncover potential novel mechanistic explanations for this relationship, we evaluated the genetic correlation between the two diseases and characterized their cross-trait pleiotropic profiles using summary statistics from updated genome-wide association studies (GWAS) on PD and IBD. 
medRxiv preprint doi: https://doi.org/10.1101/2022.01.13.22269221; this version posted January 13, 2022. The copyright holder for this preprint (which was not certified by peer review) is the author/funder, who has granted medRxiv a license to display the preprint in All rights reserved. No reuse allowed without permission.

Kang | 3

\section{Methods}

\section{Source data}

Summary statistics from two GWAS were analyzed in the present work. Genetic associations with PD were derived from a meta-analysis of 16 case-control samples from the International Parkinson's Disease Genomics Consortium (IPDGC) and 23andMe, Inc; comprising a total of 37,688 patients with clinically ascertained $(65 \%)$ or self-reported (35\%) PD and 981,372 controls. Sample characteristics and the study protocol are described elsewhere. ${ }^{17}$

The IBD GWAS summary statistics were based on a total of 59,957 participants, combining a UK sample of 25,305 European individuals $\left(\mathrm{N}_{\text {case/control }}=12,160 / 13,145\right)$ and the International Inflammatory Bowel Disease Genetics Consortium sample $\left(\mathrm{N}_{\text {case/control }}=\right.$ 12,882/21,770). ${ }^{18}$ All IBD patients were clinically ascertained, and subtype information on CD or ulcerative colitis (UC) was available. Details about study participants and protocol can be found in the original publication. ${ }^{18}$ Given the pathophysiological and genetic differences between IBD subtypes ${ }^{19-21}$, we accessed the genetic associations with both CD (combined $\left.\mathrm{N}_{\text {case/control }}=12,194 / 28,072\right)$ and UC (combined $\left.\mathrm{N}_{\text {case/control }}=12,366 / 33,609\right)$, and analyzed the two subtypes separately throughout the study.

\section{Genetic correlation analysis}

The analytical process is displayed as a flowchart in Figure 1. Genetic correlations $\left(\mathrm{r}_{\mathrm{g}}\right)$ between PD and each IBD subtype were estimated via high-definition likelihood (HDL), a full likelihood-based extension of the conventional LD score regression method that improves $r_{g}$ estimation precision by integrating more information on the linkage disequilibrium (LD) structure. $^{22,23}$

\section{Conditional false discovery rate analysis}

Genetic overlap between PD and each IBD subtype was explored using the conditional false discovery rate (cFDR) framework proposed by Andreassen et al. ${ }^{24}$ First, we visualized the extent of shared genetics affecting both traits as conditional or stratified quantile-quantile (Q-Q) plots: for any single phenotype, a conventional Q-Q plot shows the quantiles of the $\log 10$-transformed $p$-values from the corresponding GWAS (on the vertical axis) against the quantiles from an equally transformed uniform distribution corresponding to a global null distribution (on the horizontal axis); an upward deflection of the resulting curve from the line of identity reflects an enrichment of smaller than expected $p$-values, corresponding to a deviation from the null and the presence of a biological signal. For pairs of phenotypes, conditional Q-Q plots show multiple such quantile curves for the primary or target phenotype, 
medRxiv preprint doi: https://doi.org/10.1101/2022.01.13.22269221; this version posted January $13,2022$. The copyright holder for this preprint (which was not certified by peer review) is the author/funder, who has granted medRxiv a license to display the preprint in All rights reserved. No reuse allowed without permission.

Kang $\mid 4$

where each curve corresponds to a subset of variants where the $p$-values for the secondary or conditioning phenotype are selected by increasingly stringent thresholds: in the complete absence of pleiotropy, these curves should coincide, whereas in the presence of pleiotropy, we expect to see increasing upward deflection from the global null, and consequently increasing enrichment of variants associated with the primary phenotype among the subsets defined by the secondary phenotype. ${ }^{24-26}$

Next, we identified pleiotropic SNPs for PD-CD and PD-UC, respectively, by calculating the conjunctional false discovery rate (conjFDR) value for each SNP included in both PD and IBD datasets. The conjFDR is based on the cFDR and can be interpreted as a conservative estimate of the false discovery rate for a given SNP being jointly associated with both phenotypes under investigation. ${ }^{24}$ We defined pleiotropic SNPs as those with conjFDR below a threshold of 0.01 .

To assure approximate independence of the variants/ $p$-values involved, we implemented LD-based random pruning for both conditional Q-Q plots and calculation of the conjFDR (the latter based on 100 independent iterations). ${ }^{24,25}$ Further details about the concept and the recommended analytical protocol for cFDR analysis are reviewed by Smeland et al. ${ }^{25}$

\section{Functional mapping and annotation of pleiotropic variants}

Characterization and functional annotation of the pleiotropic SNPs identified from cFDR were performed via the FUMA web-based platform under the default setting if not otherwise specified. ${ }^{27}$ Using the FUMA-SNP2GENE function, we first annotated all pleiotropic SNPs via the built-in ANNOVAR tool and identified their corresponding genomic loci based on the LD pre-computed from the 1000 Genome reference panel. ${ }^{28,29}$ The direction of genetic effects of a pleiotropic locus on PD and IBD subtype was evaluated based on the proportion of concordant SNPs, defined as the variants with the product of two association coefficients $\beta$ PD $\times \beta_{\mathrm{IBD}}>0$ among the total SNPs within the locus. We regarded a locus containing $\leq 10 \%, 10$ $90 \%$, and $\geq 90 \%$ of concordant SNPs as being of antagonistic, ambiguous and concordant pleiotropy, respectively. The distribution of jointly associated SNPs and loci in different directions of pleiotropy were then visualized as Manhattan plots. To identify novel pleiotropic loci that have never been previously associated with both PD and CD, or PD and UC, we searched the PD GWAS Locus Browser (https://pdgenetics.shinyapps.io/GWASBrowser/) ${ }^{30}$ and the GWAS Catalog (https://www.ebi.ac.uk/gwas/) for all shared loci informed by our cFDR analysis, considering evidence from both GWAS and cross-phenotype analysis.

Next, we proceeded with gene prioritization via positional and expression quantitative trait loci (eQTL) mapping. We selected the GTEx v8 database for eQTL mapping, and restricted 
medRxiv preprint doi: https://doi.org/10.1101/2022.01.13.22269221; this version posted January $13,2022$. The copyright holder for this preprint (which was not certified by peer review) is the author/funder, who has granted medRxiv a license to display the preprint in All rights reserved. No reuse allowed without permission.

the tissue types to colon (including sigmoid and transverse) and substantia nigra, which are most relevant to IBD and PD pathophysiology. ${ }^{31}$ All pleiotropic SNPs were gene-mapped using the FUMA-SNP2GENE function without any filtering per functional annotations (i.e. functional consequence or Combined Annotation Dependent Depletion, CADD score). The genes prioritized via positional and eQTL mapping were then taken forward to the FUMAGENE2FUNC function to infer putative biological pathways by over-representation analysis. Significantly enriched gene sets or pathways were determined per FUMA-GENE2FUNC default parameters adjusting for multiple testing.

\section{Standard Protocol Approvals, Registrations, and Patient Consents}

For each GWAS study included in the present work, written informed consent was received from all participants and ethical approval was obtained from relevant ethical review boards. No additional ethical approval was required for our study because the analyses were based on summary statistics - i.e. without accessing individual-level genetic data.

\section{Data availability}

Full summary statistics of GWAS on IBD are publicly available at GWAS Catalog: genetic associations with CD can be downloaded at https://www.ebi.ac.uk/gwas/studies/GCST004132 and for UC at https://www.ebi.ac.uk/gwas/studies/GCST004133. Summary statistics of PD GWAS can be obtained via research project applications to 23andMe and the IPDGC. For 23andMe, the full GWAS summary statistics for the discovery data set will be made available through 23 andMe to qualified researchers under an agreement with 23andMe that protects the privacy of the 23 andMe participants. Please visit research.23andme.com/collaborate/ for more information and to apply to access the data.

\section{Code availability}

HDL analysis was performed via the software provided by Ning $\mathrm{Z}$ et al. at https://github.com/zhenin/HDL/. The cFDR analysis was performed with R version 4.0.3 using the "cfdr.pleio" package available at https://github.com/alexploner/cfdr.pleio.

\section{Results}

Weak but statistically significant genetic correlations of PD with both $\mathrm{CD}\left(r_{g}=0.06\right.$, s.e. $=$ 0.02; $P=0.01)$ and UC $\left(r_{g}=0.06\right.$, s.e. $\left.=0.03 ; P=0.03\right)$ were detected by HDL (Table 1$)$. In accordance, the successive leftward shift of curves seen in the conditional QQ plots for both trait pairs in both directions corroborated the presence of genetic overlap between PD and each IBD subtype (Figure S1). These deflections can be understood as increases in the excess of non-null SNPs for the principal phenotype when sequentially selecting sets of SNPs with 
medRxiv preprint doi: https://doi.org/10.1101/2022.01.13.22269221; this version posted January $13,2022$. The copyright holder for this preprint (which was not certified by peer review) is the author/funder, who has granted medRxiv a license to display the preprint in All rights reserved. No reuse allowed without permission.

stronger evidence of conditional associations. Interestingly, we noticed that the curves separated more prominently when more relaxed $p$ levels were conditioned on. Once the conditional $p$ cutoff reached $1 \times 10^{-5}$ (represented by the green curve in Figure S1), there was not much gain in association enrichment by requiring stronger evidence on conditional associations. Such trends might imply that the pleiotropy underlying PD and IBD is mainly attributable to SNPs with mild to moderate levels of evidence on phenotype associations but not to those with top signals for each trait.

Using cFDR analysis, we identified 1,333 and 1,915 SNPs at conjFDR below 0.01 for PDCD and PD-UC, respectively, of which 413 were common to both trait pairs (Table 2).

Overall, these jointly associated SNPs were mostly concordant with same genetic effects on the two phenotypes (72.2\% for PD-CD and 75.8\% PD-UC), located in non-exonic regions (96.8\% for PD-CD and $97.8 \%$ for PD-UC), and less likely to be deleterious due to a CADD score under 12.37 (96.4\% for PD-CD and $96.1 \%$ for PD-UC). ${ }^{32}$ The pleiotropic SNPs were then mapped to 28 independent loci for PD-CD and 22 for PD-UC, with 11 pairwise overlapping loci (Table S1-2). Amongst the 39 distinct loci in total, 30 had never been previously reported to affect both PD and IBD or either of its subtypes, and were therefore considered as novel shared loci (Table S5). As displayed in the Manhattan plots, the locuslevel pleiotropic patterns for PD-CD and PD-UC exhibited similarities in that the jointly associated loci were distributed widely across the entire genome, with at least half affecting the PD/IBD risk in the same direction; additionally, the ambiguous locus ARIH2 for PD-CD locates in the same region as the ambiguous PD-UC locus at IP6K2 (Figure 2, Table S5). The two trait pairs however differed in their strongest association, which was located in the SLC2A13 locus on chromosome 12 (shared with LRRK2) for PD-CD, but in the HLA-DRA locus on chromosome 6 for PD-UC. Interestingly, three of the 11 pairwise common loci had different pleiotropic directions: ILIR2 on chromosome 2 and HISTIH2BO (shared with PDUC locus ZNF165) on chromosome 6 were antagonistic for PD-CD but concordant for PDUC, while TRIM10 (shared with PD-UC locus $H L A-W$ ) on chromosome 6 was concordant for PD-CD but antagonistic for PD-UC. The discrepancy of pleiotropic direction for common loci mirrors the earlier finding that CD and UC may be genetically distinctive. ${ }^{20}$

Positional and eQTL mapping prioritized 316 and 303 genes for PD-CD and PD-UC, respectively, among which 197 pairwise overlapped (Table 2, S3-4). For both trait pairs, around $80 \%$ of the eQTL mapped genes are differentially expressed in colon but not substantia nigra. Following the FUMA-GENE2FUNC procedure, 12 KEGG pathways for PDCD and 16 for PD-UC (Figure 3, Table S6), as well as a wide range of Gene Ontology (GO) 
medRxiv preprint doi: https://doi.org/10.1101/2022.01.13.22269221; this version posted January $13,2022$. The copyright holder for this preprint (which was not certified by peer review) is the author/funder, who has granted medRxiv a license to display the preprint in All rights reserved. No reuse allowed without permission.

terms (results not shown) were found to be over-represented by all the genes prioritized from both mapping methods and including both tissues. Comparison of KEGG results showed that 11 of the 12 PD-CD pathways, all related to host immunity and/or autoimmune diseases, were also significantly enriched in PD-UC genes; whereas the "KEGG_LYSOSOME" pathway, which comprised one of the most common PD susceptibility gene GBA, was identified for PD-CD but not PD-UC. Beyond the immune-dominated mechanisms, the pathways specific to PD-UC further extended to neuronal development and hematopoietic development.

\section{Discussion}

Despite a modest genetic correlation, we discovered robust evidence for a genetic link between PD and each IBD subtype, underpinned by many shared genomic loci. The identified genetic overlap is complex at the locus- and gene-levels, indicating the presence of both common etiology and antagonistic pleiotropy between PD and IBD. Nonetheless, at the functional level, the PD-IBD genetic overlap converges to a set of pathways involved in host immunity and/or autoimmunity.

The biological connection between PD and IBD has been supported by a growing body of evidence. ${ }^{4,14,16}$ The genetic correlation between PD and each IBD subtype however was weak in our material (albeit conventionally statistically significant), in contrast to the evidence for pleiotropic enrichment seen in the conditional Q-Q plots. Possible explanations for this unexpectedly weak genetic correlation may be found in the cFDR results. First, the PD-IBD pleiotropy was observed to be mainly due to SNPs with GWAS $p$-values above the genomewide significance level, whereas such non-significant variants are largely under-weighted in the estimation of genetic correlation. ${ }^{22}$ Second, the genetic overlap between PD and each IBD subtype comprises antagonistic pleiotropy, which may cancel out the effects of shared risk loci and lead to an underestimated genetic correlation. ${ }^{33}$ Taken together, these two points emphasize the importance of including not only SNPs with genome-wide significance but also those with moderate association $p$-values, and considering the direction of genetic effects in future explorations of pleiotropy for complex traits.

Several previously established shared loci, such as HLA and LRRK2, are replicated by our findings. Moreover, we discovered 30 novel pleiotropic loci, including 10 known risk loci for either PD (RAB7L1 and ARIH2/IP6K2) or IBD (KIF21B/MROH3P, IL1R2, HNRNPA1P41, GLYAT, PNKD:TMBIM1, LITAF, ADCY7 and PLCG2). ${ }^{17,18,34-40}$ Amongst these, MROH3P is an IBD risk locus that was initially nominated as a shared locus for PD-CD but not PD-UC. ${ }^{16}$ Here, we confirmed its concordant pleiotropy for PD-CD and extended it further to PD-UC. 
medRxiv preprint doi: https://doi.org/10.1101/2022.01.13.22269221; this version posted January $13,2022$. The copyright holder for this preprint (which was not certified by peer review) is the author/funder, who has granted medRxiv a license to display the preprint in All rights reserved. No reuse allowed without permission.

The association of $M R O H 3 P$ with colonic expression of Clorf106, an IBD susceptibility gene encoding a protein that is critical for epithelial homeostasis, suggests a role of intestinal barrier dysfunction in PD and IBD pathogenesis. ${ }^{41}$ For another IBD risk locus ILIR2, which harbors the encoding gene for interleukin-1 receptor 2, we found conflicting pleiotropy for PD-CD (antagonistic) versus PD-UC (concordant). This is not intuitive because the immune regulatory role of interleukin-1 receptor 2 in IBD has been well documented. ${ }^{42}$ Interestingly, emerging data also associated IL1R2 polymorphisms with PD risk. ${ }^{43-45}$ Although our eQTL mapping results do not support any functional impact of IL1R2 variation on gene expression in colon or substantia nigra, future research is warranted. The PD risk locus at $A R I H 2 / I P 6 K 2$ is also noteworthy for its association with the expression of candidate PD gene WDR6 and 4 other genes (NCKIPSD, GMPPB, PRKAR2A, and AMT) in both colon and substantia nigra in our data. ${ }^{46}$ Intriguingly, the pleiotropic direction of ARIH2/IP6K2 locus for PD-CD and PDUC remained ambiguous in our data and needs subsequent studies to clarify. Lastly, the 20 pleiotropic loci with no documented association with any studied traits contained 4 eQTLs for expression of 6 genes in both colon and substantia nigra; however, none of them were overrepresented in any KEGG gene-sets.

In contrast to the complexity of locus-level pleiotropy, the biological pathways shared by PD and IBD are dominated by immune-related mechanisms. As displayed in Figure 3, the 12 PD-CD and 16 PD-UC KEGG pathways overlapped in 11 gene-sets, where the enriched genes are predominantly HLA members that are responsible for antigen presentation and immune regulation. ${ }^{47}$ Notably, four autoimmune phenotypes - type 1 diabetes, systemic lupus erythematosus, autoimmune thyroid disease and asthma - were commonly identified for both PD-CD and PD-UC, in line with Witoelar et al's earlier report. ${ }^{16}$ Another 5 terms were implicated in dysregulation of immune response to external stimuli, such as transplanted grafts (allograft rejection and graft versus host disease) and pathogens (viral myocarditis, intestinal immune network for IgA production, and Leishmania infection), suggesting a pivotal role of host defense mechanisms in the PD-IBD shared biology.

Strengths of our study are the implementation of the powerful contemporary methods and the utilization of the most updated GWAS data. The reproducibility of our findings is enhanced by the choice of a conservative conjFDR threshold of 0.01. To our knowledge, we are the first to make the distinction between concordant and antagonistic pleiotropy in research on the PD-IBD connection, which provides crucial information for translational clinical and pharmaceutical innovation. The present work also has limitations. First, functional validation of detected genetic elements is beyond our scope, restricting causal 
medRxiv preprint doi: https://doi.org/10.1101/2022.01.13.22269221; this version posted January $13,2022$. The copyright holder for this preprint (which was not certified by peer review) is the author/funder, who has granted medRxiv a license to display the preprint in All rights reserved. No reuse allowed without permission.

interpretation of our findings. Nevertheless, we performed multi-hierarchical bioinformatic analyses to facilitate biological inference. Second, based on the data available to us, we were not able to clarify the pleiotropic direction for all identified genetic overlap between PD and IBD. However, the pathway analysis indicated that the immune system remains the most promising common target for the two diseases, regardless of the sophisticated pleiotropic pattern at locus or gene levels.

In conclusion, our genetic evidence supports the notion that PD and IBD are biologically connected phenotypes and indicate the immune system as a promising target for therapeutic development for both PD and IBD.

Acknowledgements: The authors thank Dr. Ida Karlsson from Karolinska Institutet for suggestions on choice and application of functional annotation tools, Dr. Zheng Ning from Karolinska Institutet for assistance on running the HDL package. The authors would also like to thank the research participants and employees of the IPDGC and 23andMe for making this work possible. Contributors to the IPDGC are listed at https://pdgenetics.org/partners.

Author Contributions: X.K. had full access to the data analyzed in the study and take responsibility for the integrity of the data and the accuracy of data analysis.

Concept and design: X.K., A.P., and K.W..

Acquisition, analysis, or interpretation of data: X.K., A.P., Y.W., and K.W..

Drafting of the manuscript: X.K..

Critical revision of the manuscript for important intellectual content: All authors.

Statistical analysis: X.K., A.P..

Obtained funding: N.L.P. and K.W..

Administrative, technical, or material support: K.W..

Supervision: A.P., D.M.W., N.L.P., J.F.L., and K.W.. 
medRxiv preprint doi: https://doi.org/10.1101/2022.01.13.22269221; this version posted January 13,2022 . The copyright holder for this preprint (which was not certified by peer review) is the author/funder, who has granted medRxiv a license to display the preprint in All rights reserved. No reuse allowed without permission.

\section{References}

1. Klingelhoefer L, Reichmann H. Pathogenesis of Parkinson disease--the gut-brain axis and environmental factors. Nat Rev Neurol. 2015;11(11):625-636.

2. Menozzi E, Macnaughtan J, Schapira AHV. The gut-brain axis and Parkinson disease: clinical and pathogenetic relevance. Ann Med. 2021;53(1):611-625.

3. Nikolaus S, Schreiber S. Diagnostics of inflammatory bowel disease. Gastroenterology. 2007;133(5):1670-1689.

4. Zhu Y, Yuan M, Liu Y, et al. Association between inflammatory bowel diseases and Parkinson's disease: systematic review and meta-analysis. Neural Regen Res. 2022;17(2):344-353.

5. Park S, Kim J, Chun J, et al. Patients with Inflammatory Bowel Disease Are at an Increased Risk of Parkinson's Disease: A South Korean Nationwide Population-Based Study. J Clin Med. 2019;8(8).

6. Wan QY, Zhao R, Wu XT. Older patients with IBD might have higher risk of Parkinson's disease. Gut. 2020;69(1):193-194.

7. Houser MC, Caudle WM, Chang J, et al. Experimental colitis promotes sustained, sexdependent, T-cell-associated neuroinflammation and parkinsonian neuropathology. Acta Neuropathol Commun. 2021;9(1):139.

8. Brudek T. Inflammatory Bowel Diseases and Parkinson's Disease. J Parkinsons Dis. 2019;9(s2):S331-S344.

9. Antonini M, Lo Conte M, Sorini C, Falcone M. How the Interplay Between the Commensal Microbiota, Gut Barrier Integrity, and Mucosal Immunity Regulates Brain Autoimmunity. Front Immunol. 2019;10:1937.

10. Lee HS, Lobbestael E, Vermeire S, Sabino J, Cleynen I. Inflammatory bowel disease and Parkinson's disease: common pathophysiological links. Gut. 2021;70(2):408-417.

11. Chen QQ, Haikal C, Li W, Li JY. Gut Inflammation in Association With Pathogenesis of Parkinson's Disease. Front Mol Neurosci. 2019;12:218.

12. Schaeffer E, Kluge A, Bottner M, et al. Alpha Synuclein Connects the Gut-Brain Axis in Parkinson's Disease Patients - A View on Clinical Aspects, Cellular Pathology and Analytical Methodology. Front Cell Dev Biol. 2020;8:573696.

13. Stolzenberg E, Berry D, Yang, et al. A Role for Neuronal Alpha-Synuclein in Gastrointestinal Immunity. J Innate Immun. 2017;9(5):456-463.

14. Hui KY, Fernandez-Hernandez $\mathrm{H}, \mathrm{Hu}$ J, et al. Functional variants in the LRRK2 gene confer shared effects on risk for Crohn's disease and Parkinson's disease. Sci Transl Med. 2018;10(423).

15. Herrick MK, Tansey MG. Is LRRK2 the missing link between inflammatory bowel disease and Parkinson's disease? NPJ Parkinsons Dis. 2021;7(1):26.

16. Witoelar A, Jansen IE, Wang Y, et al. Genome-wide Pleiotropy Between Parkinson Disease and Autoimmune Diseases. JAMA Neurol. 2017;74(7):780-792.

17. Nalls $\mathrm{MA}$, Blauwendraat $\mathrm{C}$, Vallerga $\mathrm{CL}$, et al. Identification of novel risk loci, causal insights, and heritable risk for Parkinson's disease: a meta-analysis of genome-wide association studies. Lancet Neurol. 2019;18(12):1091-1102.

18. de Lange KM, Moutsianas L, Lee JC, et al. Genome-wide association study implicates immune activation of multiple integrin genes in inflammatory bowel disease. Nat Genet. 2017;49(2):256-261. 
medRxiv preprint doi: https://doi.org/10.1101/2022.01.13.22269221; this version posted January 13,2022 . The copyright holder for this preprint (which was not certified by peer review) is the author/funder, who has granted medRxiv a license to display the preprint in All rights reserved. No reuse allowed without permission.

Kang | 11

19. Yang L, Tang S, Baker SS, et al. Difference in Pathomechanism Between Crohn's Disease and Ulcerative Colitis Revealed by Colon Transcriptome. Inflamm Bowel Dis. 2019;25(4):722-731.

20. Waterman M, Xu W, Stempak JM, et al. Distinct and overlapping genetic loci in Crohn's disease and ulcerative colitis: correlations with pathogenesis. Inflamm Bowel Dis. 2011;17(9):1936-1942.

21. Wu F, Dassopoulos T, Cope L, et al. Genome-wide gene expression differences in Crohn's disease and ulcerative colitis from endoscopic pinch biopsies: insights into distinctive pathogenesis. Inflamm Bowel Dis. 2007;13(7):807-821.

22. Bulik-Sullivan BK, Loh PR, Finucane HK, et al. LD Score regression distinguishes confounding from polygenicity in genome-wide association studies. Nat Genet. 2015;47(3):291-295.

23. Ning $Z$, Pawitan $Y$, Shen $X$. High-definition likelihood inference of genetic correlations across human complex traits. Nat Genet. 2020;52(8):859-864.

24. Andreassen OA, Djurovic $S$, Thompson WK, et al. Improved detection of common variants associated with schizophrenia by leveraging pleiotropy with cardiovasculardisease risk factors. Am J Hum Genet. 2013;92(2):197-209.

25. Smeland OB, Frei O, Shadrin A, et al. Discovery of shared genomic loci using the conditional false discovery rate approach. Hum Genet. 2020;139(1):85-94.

26. Liley J, Wallace C. A pleiotropy-informed Bayesian false discovery rate adapted to a shared control design finds new disease associations from GWAS summary statistics. PLoS Genet. 2015;11(2):e1004926.

27. Watanabe $K$, Taskesen E, van Bochoven A, Posthuma D. Functional mapping and annotation of genetic associations with FUMA. Nat Commun. 2017;8(1):1826.

28. Auton A, Brooks LD, Durbin RM, et al. A global reference for human genetic variation. Nature. 2015;526(7571):68-74.

29. Wang K, Li M, Hakonarson H. ANNOVAR: functional annotation of genetic variants from high-throughput sequencing data. Nucleic Acids Res. 2010;38(16):e164.

30. Grenn FP, Kim JJ, Makarious MB, et al. The Parkinson's Disease Genome-Wide Association Study Locus Browser. Mov Disord. 2020;35(11):2056-2067.

31. Battle A, Brown CD, Engelhardt BE, et al. Genetic effects on gene expression across human tissues. Nature. 2017;550(7675):204-213.

32. Kircher M, Witten DM, Jain P, O'Roak BJ, Cooper GM, Shendure J. A general framework for estimating the relative pathogenicity of human genetic variants. Nat Genet. 2014;46(3):310-315.

33. Bulik-Sullivan B, Finucane HK, Anttila V, et al. An atlas of genetic correlations across human diseases and traits. Nat Genet. 2015;47(11):1236-1241.

34. Wu Y, Murray GK, Byrne EM, Sidorenko J, Visscher PM, Wray NR. GWAS of peptic ulcer disease implicates Helicobacter pylori infection, other gastrointestinal disorders and depression. Nat Commun. 2021;12(1):1146.

35. Barrett JC, Hansoul S, Nicolae DL, et al. Genome-wide association defines more than 30 distinct susceptibility loci for Crohn's disease. Nat Genet. 2008;40(8):955-962.

36. Liu JZ, van Sommeren S, Huang $\mathrm{H}$, et al. Association analyses identify 38 susceptibility loci for inflammatory bowel disease and highlight shared genetic risk across populations. Nat Genet. 2015;47(9):979-986. 
medRxiv preprint doi: https://doi.org/10.1101/2022.01.13.22269221; this version posted January $13,2022$. The copyright holder for this preprint (which was not certified by peer review) is the author/funder, who has granted medRxiv a license to display the preprint in All rights reserved. No reuse allowed without permission.

37. Jostins L, Ripke S, Weersma RK, et al. Host-microbe interactions have shaped the genetic architecture of inflammatory bowel disease. Nature. 2012;491(7422):119124.

38. Ellinghaus D, Jostins L, Spain SL, et al. Analysis of five chronic inflammatory diseases identifies 27 new associations and highlights disease-specific patterns at shared loci. Nat Genet. 2016;48(5):510-518.

39. Luo $Y$, de Lange KM, Jostins $L$, et al. Exploring the genetic architecture of inflammatory bowel disease by whole-genome sequencing identifies association at ADCY7. Nat Genet. 2017;49(2):186-192.

40. Li YR, Li J, Zhao SD, et al. Meta-analysis of shared genetic architecture across ten pediatric autoimmune diseases. Nat Med. 2015;21(9):1018-1027.

41. Thomas H. IBD: Functional characterization of an IBD risk gene. Nat Rev Gastroenterol Hepatol. 2018;15(4):190-191.

42. Peters VA, Joesting JJ, Freund GG. IL-1 receptor 2 (IL-1R2) and its role in immune regulation. Brain Behav Immun. 2013;32:1-8.

43. Gao T, Zheng R, Ruan Y, et al. Association of ZNF184, IL1R2, LRRK2, ITPKB, and PARK16 with sporadic Parkinson's disease in Eastern China. Neurosci Lett. 2020;735:135261.

44. Li G, Cui S, Du J, et al. Association of GALC, ZNF184, IL1R2 and ELOVL7 With Parkinson's Disease in Southern Chinese. Front Aging Neurosci. 2018;10:402.

45. Smeland OB, Shadrin A, Bahrami S, et al. Genome-wide Association Analysis of Parkinson's Disease and Schizophrenia Reveals Shared Genetic Architecture and Identifies Novel Risk Loci. Biol Psychiatry. 2021;89(3):227-235.

46. Kia DA, Zhang D, Guelfi S, et al. Identification of Candidate Parkinson Disease Genes by Integrating Genome-Wide Association Study, Expression, and Epigenetic Data Sets. JAMA Neurol. 2021;78(4):464-472.

47. Paola Cruz-Tapias JC, and Juan-Manuel Anaya. Chapter 10 Major histocompatibility complex: Antigen processing and presentation. In: Anaya JM, Shoenfeld Y, RojasVillarraga A, Levy RA, Cervera R, eds. Autoimmunity: From Bench to Bedside. Bogota (Colombia)2013. 
medRxiv preprint doi: https://doi.org/10.1101/2022.01.13.22269221; this version posted January $13,2022$. The copyright holder for this preprint (which was not certified by peer review) is the author/funder, who has granted medRxiv a license to display the preprint in All rights reserved. No reuse allowed without permission.

\section{Figure Legends}

Figure 1. Schematic diagram of the analytical procedures implemented in the study. Abbreviations: cFDR, conditional false discovery rate; PD, Parkinson disease; IBD, inflammatory bowel disease; SNP, single nucleotide polymorphism.

Figure 2. Manhattan plots for jointly associated variants and loci in different directions of pleiotropy for Parkinson disease and Crohn's disease (A) or ulcerative colitis (B). The y-axis denotes the - $\log 10$-transformed conjunctional false discovery rate (conjFDR) values for each single nucleotide polymorphism (SNP). The jointly associated SNPs with conjFDR $<0.01$ were highlighted in green if being concordant (with same genetic effects on the two phenotypes), or red if being antagonistic (with opposite genetic effects on the two phenotypes). The jointly associated loci were labelled with the corresponding gene name, and colored in green, red or blue if the direction of locus pleiotropy is concordant, antagonistic, or ambiguous, respectively.

Abbreviations: PD, Parkinson disease; CD, Crohn's disease; UC, ulcerative colitis; conjFDR, conjunctional false discovery rate.

Figure 3. The KEGG pathways over-represented by prioritized genes for Parkinson disease and Crohn's disease (A) or ulcerative colitis (B). The - $\log 10$ adjusted $P$-value denotes the $\log 10$-transformed $P$-value from gene-set enrichment analysis after multiple test correction. Abbreviations: PD, Parkinson disease; CD, Crohn's disease; UC, ulcerative colitis. 
medRxiv preprint doi: https://doi.org/10.1101/2022.01.13.22269221; this version posted January $13,2022$. The copyright holder for this preprint (which was not certified by peer review) is the author/funder, who has granted medRxiv a license to display the preprint in All rights reserved. No reuse allowed without permission.

Kang | 14

Table 1. Genetic correlations between Parkinson disease and each subtype of inflammatory bowel disease.

\begin{tabular}{cccc}
\hline \hline Phenotypes & $r_{g}$ & Standard error & $p$ \\
\hline PD and CD & 0.06 & 0.02 & 0.01 \\
PD and UC & 0.06 & 0.03 & 0.03
\end{tabular}

Abbreviations: PD, Parkinson disease; $\mathrm{CD}$, Crohn disease; UC, ulcerative colitis. 
medRxiv preprint doi: https://doi.org/10.1101/2022.01.13.22269221; this version posted January $13,2022$. The copyright holder for this preprint (which was not certified by peer review) is the author/funder, who has granted medRxiv a license to display the preprint in All rights reserved. No reuse allowed without permission.

Table 2. Genome-wide pleiotropy for Parkinson disease and inflammatory bowel disease.

\begin{tabular}{r|c|c}
\hline \hline & PD and Crohn disease & PD and ulcerative colitis \\
\hline Pleiotropic SNPs at conjFDR < 0.01 \\
\hline Total, n (\%) & $1,333(100 \%)$ & $1,915(100 \%)$ \\
\hline Concordant SNPs, n (\%) & $962(72.2 \%)$ & $1,452(75.8 \%)$ \\
\hline Exonic SNPs, n (\%) & $42(3.2 \%)$ & $42(2.2 \%)$ \\
\hline
\end{tabular}

Independent loci identified from the pleiotropic SNPs, by direction of pleiotropy ${ }^{1}$

\begin{tabular}{r|c|c}
\hline Total, n (\%) & $28(100 \%)$ & $22(100 \%)$ \\
\hline Concordant, n (\%) & $14(50.0 \%)$ & $13(59.1 \%)$ \\
\hline Antagonistic, n (\%) & $13(46.4 \%)$ & $8(36.4 \%)$ \\
\hline Ambiguous, n (\%) & $1(3.6 \%)$ & $1(4.5 \%)$ \\
\hline
\end{tabular}

Prioritized genes, by mapping method

\begin{tabular}{r|c|c}
\hline Total & 316 & 303 \\
\hline eQTL, colon only & 112 & 100 \\
\hline eQTL, substantia nigra only & 2 & 1 \\
\hline eQTL, colon \& substantia nigra & 21 & 25 \\
\hline
\end{tabular}

Over-represented gene sets or pathways with adjusted $p<0.05^{3}$

\begin{tabular}{r|c|c}
\hline KEGG pathways & 12 & 16 \\
\hline GO term: biological process & 62 & 78 \\
\hline GO term: cellular component & 41 & 46 \\
\hline GO term: molecular function & 6 & 12 \\
\hline
\end{tabular}

${ }^{1}$ Direction of pleiotropy for a locus is defined by the proportion of concordant SNPs divided by the total number of SNPs within the locus: concordant if $>90 \%$, antagonistic if $<10 \%$, and ambiguous if $10-90 \%$.

${ }^{2}$ Includes sigmoid and transverse

${ }^{3}$ Based on genes identified by both positional and eQTL mapping via FUMA-GENE2FUNC.

Abbreviations: PD, Parkinson disease; SNP, single nucleotide polymorphism; conjFDR, conjunctional false discovery rate; CADD, combined annotation dependent depletion; eQTL, expression quantitative trait loci; GO, gene ontology; KEGG, kyoto encyclopedia of genes and genomes. 


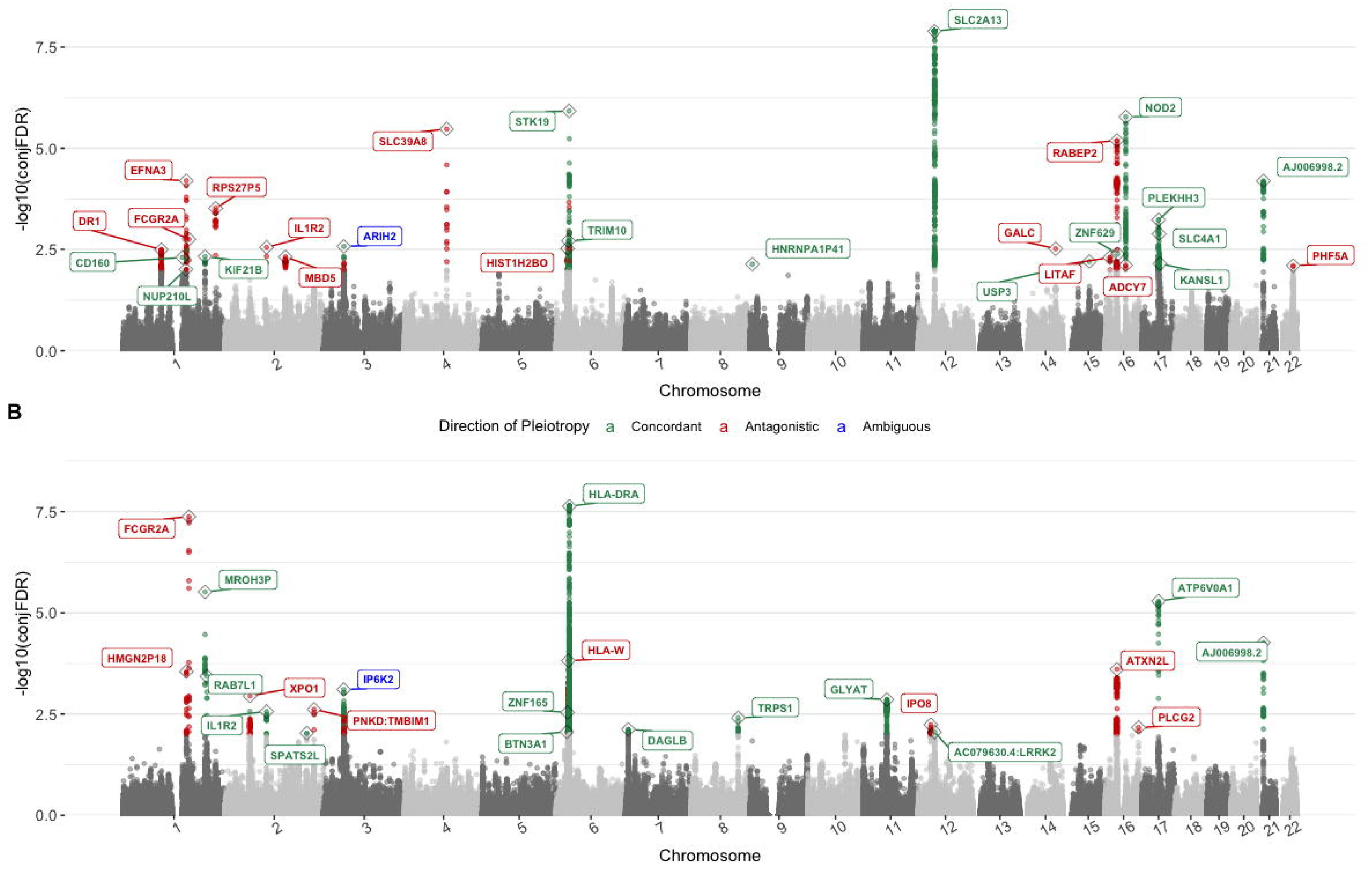


KEGG ALLOGRAFT REJECTION KEGG_GRAFT_VERSUS_HOST_DISEASE KEGG_TYPE_IDDIABETES_MELLITUS KEGG_SYSTEMIC LUPUS ERYTHEMATOSUS KEGG AUTOIMMUNE THYROID DISEASE KEGG VIRAL MYOCARDITIS KEGG_ANTIGEN_PROCESSING_AND_PRESENTATION KEGG ASTHMA G INTESTINAL IMMUNE NETWORK FOR IGA PRODUCTION -

KEGG CELL ADHESION MOLECULES CAMS KEGG_LEISHMANIA_INFECTION KEGG_LYSOSOME -

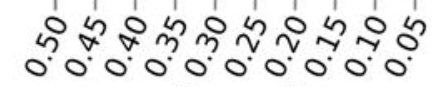

Proportion

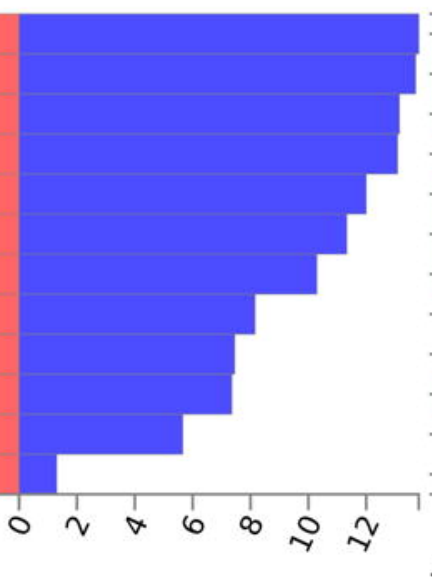

-log10 adjusted P-value

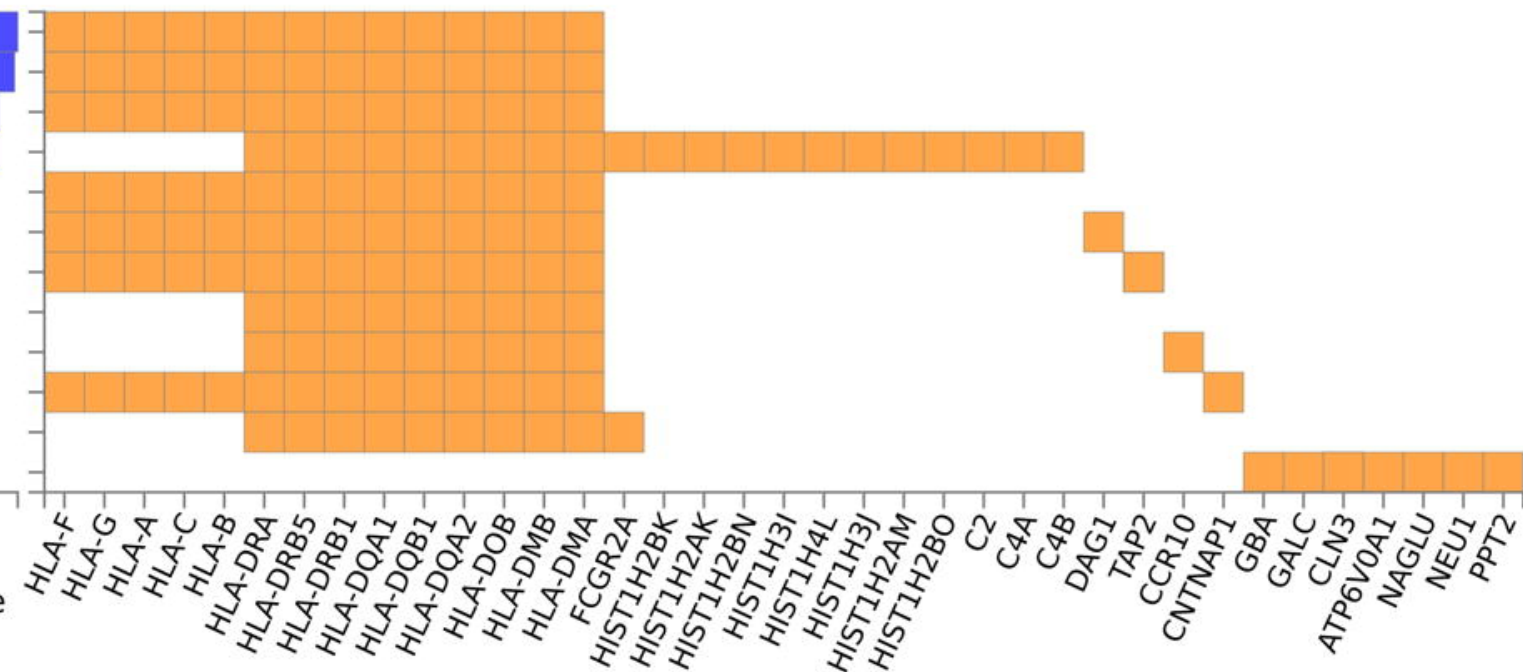
Proportion of overlapping Enrichment P-value
genes in gene sets

KEGG_ANTIGEN PROCESSING AND PRESENTATION KEGG_TYPE_I_DIABETES_MELLITUS KEGG_ALLOGRAFT_REJECTION KEGG_GRAF__ERSUS_HOST_DISEASE KEGG_AUTOIMMUNE_THYROID_DISEASE KEGG_ASTHMA KEGG_CELL_ADHESION_MOLECULES_CAMS
KEGG_SYSTEMIC_LUPUS_ERYTHEMATOSUS INTESTINAL IMMUNE NETWORK FOR IGA_PRODUCTION KEGG NATURAL KILLER CELL MEDIATED CYTOTOXICITY KEGG_LEISHMANIA_INFECTION KEGG_ENDOCYTOSIS
KEGG_HEMATOPOIETIC_CELL_LINEAGE
KEGG_AXON_GUIDANCE KEGG_AXON_GUIDANCE
KEGG_GLYCOSAMINOGLYCAN_DEGRADATION
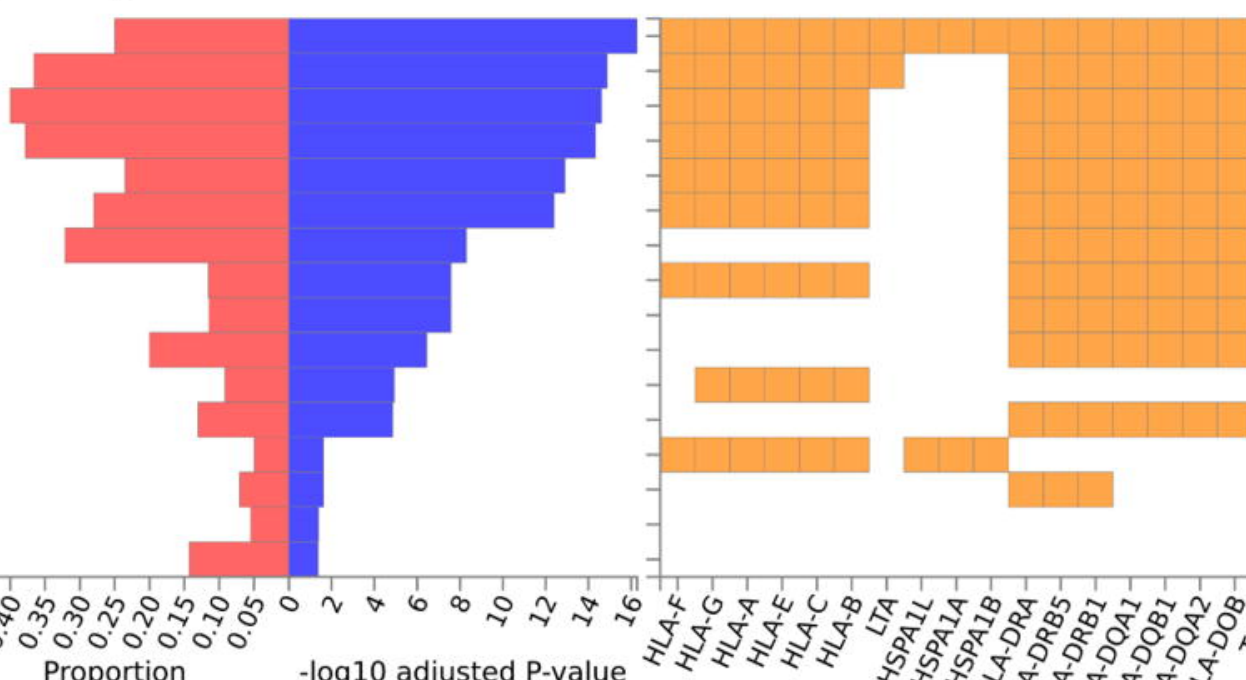

Proportion

$-\log 10$ adjusted P-value overlapping genes

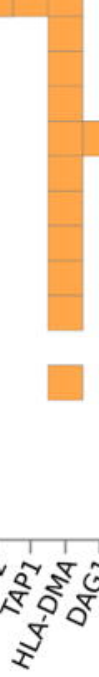

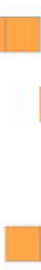

$\square$

1

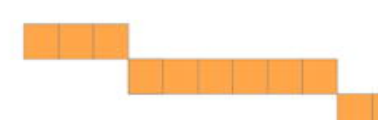

